\title{
A Misdiagnosed Metastatic Squamous Cell Carcinoma of the Vulva
}

\author{
Tito Brambullo (iD*, Gian Paolo Azzena, Giuseppe Masciopinto, Paolo Toninello (iD, Bernardo BiffoliiD, Alberto De Lazzari(i) \\ Department of Neurosciences, University of Padua, Padova, Italy
}

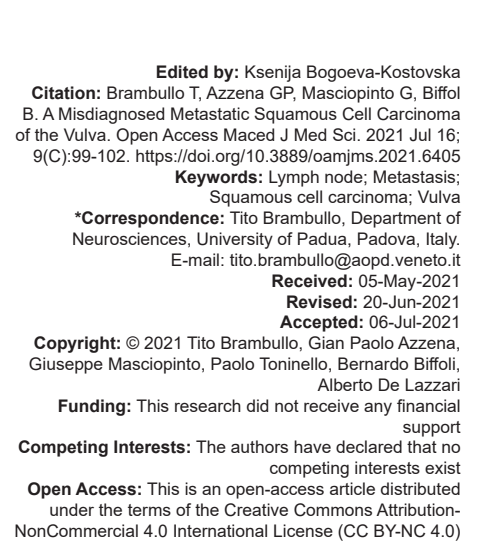

\section{Introduction}

Vulvar squamous cell carcinoma (SCC) is considered a rare tumor of female genitalia, because of an incidence ranging from 1 to $2 / 100,000$ women [1].

Vulvar SCC can be HPV-related and a nonHPV-related, the first usually arises in younger women, the second affects more frequently elder ones.

At presentation, tumor size and inguinofemoral nodes status represents the most important prognostic factor in vulvar SCC [2].

Vulvar SCC is staged according to TNM and the International Federation of Gynecology and Obstetrics staging systems [3].

The size of the primary tumor $(T)$, the status of regional nodes $(\mathrm{N})$, and the presence of distant metastasis $(\mathrm{M})$ constitute the parameters on which the staging is calculated.

Recently, some other parameters of primary tumor have been evaluated in order to define a highrisk SCC subtype, these are the size (diameter $>2 \mathrm{~cm}$ ), the in-depth growth (stromal invasion) (alternatively the Breslow measurement is considered equivalent), the perineural invasion and the extent to adjacent anatomical structures such as the urethra, bladder, anus, and vagina [4].

When at least one of these parameters is present the vulvar SCC can be defined "locally advanced," and correlates to high rates of local recurrence and node involvement [5] and with worse overall survival.

Likewise, a recurrent vulvar SCC after radical excision is to be considered locally advanced.

\section{Case History}

A 76-year-old woman was hospitalized in the internal medicine department for acute thrombosis of common and superficial femoral vein associated with edema of the right inferior limb, a skin ulceration was also present on the ipsilateral groin (Figure 1).

The diagnosis was posed after a CT scan, that also showed soft tissue erosion forming a cavity of $12 \times$ $8 \times 4 \mathrm{~cm}$ localized on the right inguinal groove (Figure 2). 


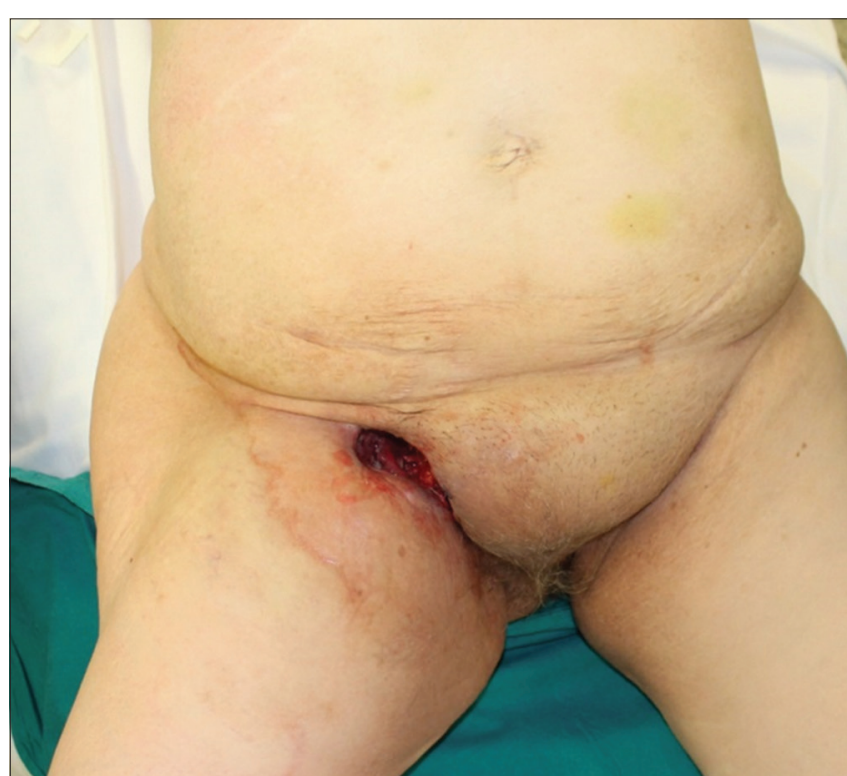

Figure 1: Right groin skin lesion at presentation

The skin around the ulceration was deeply undermined, no signs of granulation were present, and a slough film was covering all the subcutaneous fatty layer.

Vein thrombosis etiology was suggested being the external compression caused by a huge groin abscess that had enlarged up to skin breakdown.

Plastic surgery consultation was required to evaluate the options for local treatment.

Biochemical parameters were in range, except for arterial pressure and glycemia, due to hypertension and diabetes, both drugs treated.

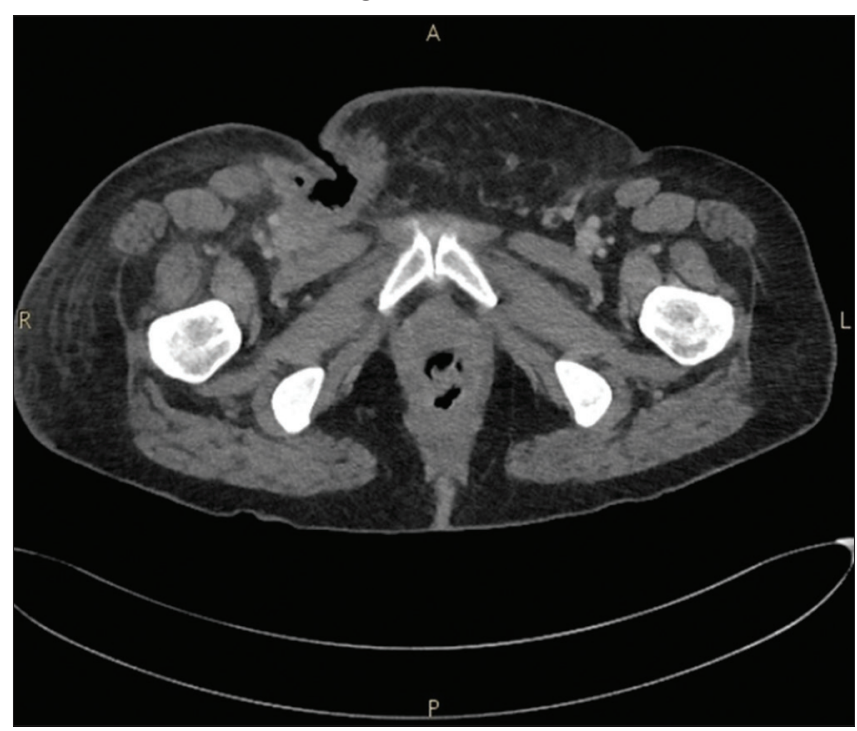

Figure 2: CT scan. A dense altered tissue surrounds the right groin cavity extending to femoral vessels

The patient interview revealed a history of SCC of the vulva (diameter $3 \mathrm{~cm}$, moderately differentiated, no vascular, or lymphatic invasion), successfully treated 4 years before (April 2016) with simple vulvectomy (resection of the clitoris and minor labia with close free margins, the narrowest free margin was $2 \mathrm{~mm}$ ) (pT1b - stage IB).
The staging was negative for regional and distant metastasis, so no adjuvant chemo/radiotherapy was administered.

After 2 years (October 2018) patient developed a local recurrence (diameter $2.8 \mathrm{~cm}$, ulcerated, moderately differentiated) so underwent radical vulvectomy with bilateral inguinal dissection, excision margins resulted free (the narrowest free margin was $2 \mathrm{~mm}$ ), even if close and no lymph node metastasis were detected of 22 lymph nodes retrieved ( $\mathrm{pT} 1 \mathrm{~b}$ N0 MO - stage IB)

During the immediate postoperative period, patient developed an abscess of the right groin, that was successfully drained, the follow-up was uneventful.

At the time of plastic consultation, in February 2020, given the history and local conditions, incisional biopsies of lesion margins were performed under local anesthesia, that revealed SCC cell nests.

After a full-through discussion with patient and her relatives on treatment options and prognosis, a multidisciplinary surgical approach was planned, consisting of wide surgical resection of the groin, part of mons pubis, and right pelvic iliac-obturator lymphadenectomy (Figure 3).

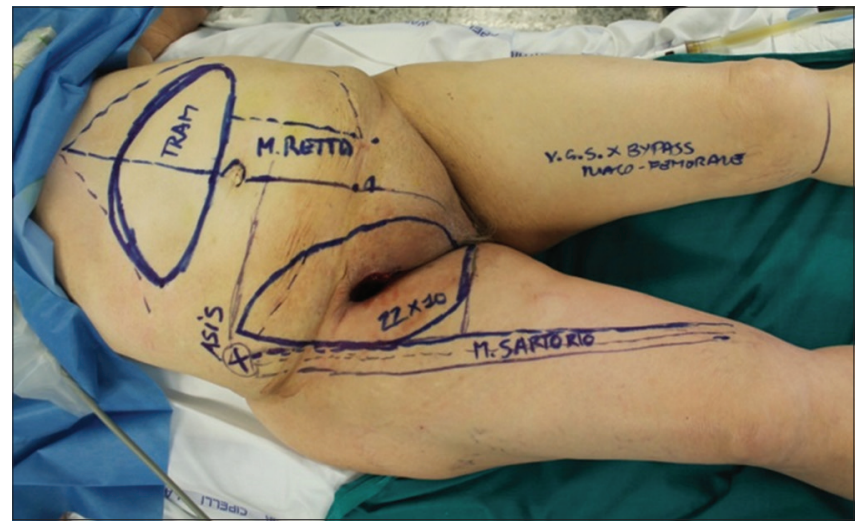

Figure 3: Preoperative planning of wide groin excision and abdominal skin island of left rectus muscle TRAM flap

Vascular surgeon did not pose indication to vein reconstruction with graft, given the time intervening since thrombosis occurred and the absence of distal limb congestion.

Femoral artery excision was performed due to the absence of a clear margin, and reconstruction was accomplished with interposed great saphenous vein graft.

The plastic reconstruction consisted of harvest of transverse rectus abdominal flap, that was transposed inferiorly to repair the right groin (Figures 4 and 5).

An abdominal mesh was then applied to the donor area in order to reduce the risk of post-incisional hernia.

Postoperative healing was uneventful, and patient was discharged 2 weeks later.

Pathologist confirmed free margins of excision, the massive extracapsular spread, and tissues necrosis 
did not allow to definitely assess if the tumor relapse origin was a primary cell nest or a secondary lymph node metastasis, pelvic lymph nodes resulted in negative ( $\mathrm{pT} 1 \mathrm{~b}, \mathrm{~N} 3, \mathrm{M0}$ - stage IV A).

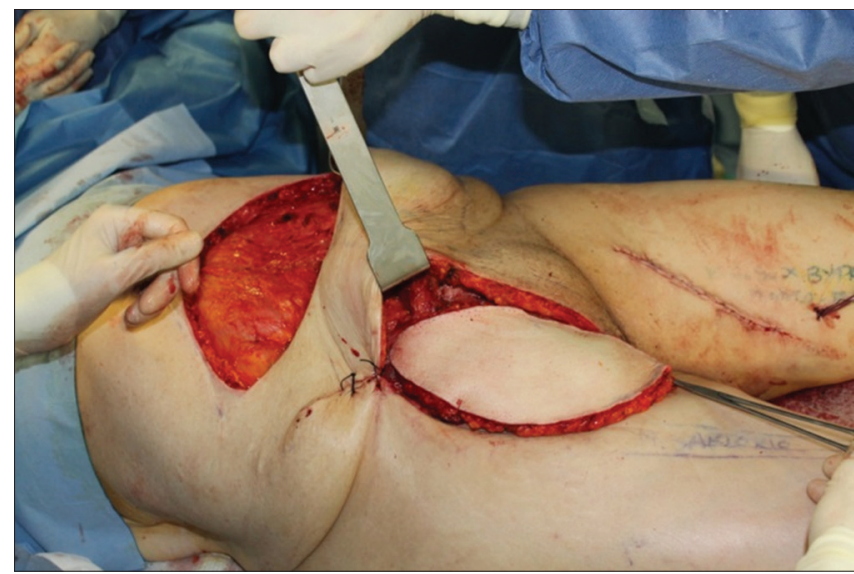

Figure 4: Abdominal TRAM flap setting into right groin

In consideration of extensive invasion and limb major vessels involvement, adjuvant radiotherapy was considered but not indicated due to the patient poor general conditions.

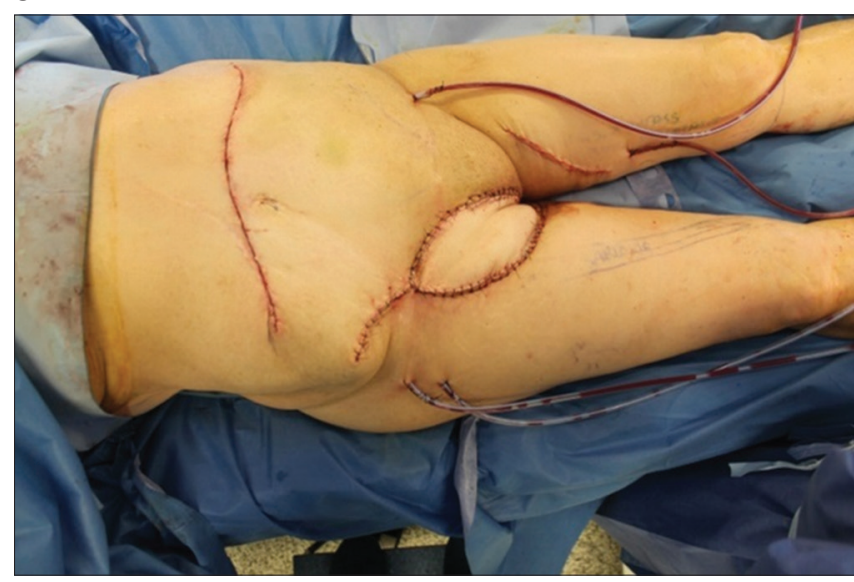

Figure 5: Final result after TRAM flap inset into right groin and closure of donor area

At 3 months follow-up no local recurrence was evident, but after 8 months patient developed several cutaneous nodules external to surgical margins, thus she was proposed for immunotherapy and palliative care.

She died 1 month later.

\section{Discussion}

We present the case of a misdiagnosed metastatic SCC of the vulva.

The patient underwent two surgeries with radical intent and the margins and regional nodes were proved to be free.

Hence, the treatment can be defined appropriate and successful [6], but close margins of resection (up few $\mathrm{mm}$ ) may be inadequate to guarantee a long disease-free survival.

When the malignancy is evident is always arduous make the patient understand the need for a wide excision (hemi- or total-vulvectomy) [7].

The patient's high expectations related to function preservation and aesthetics may lead to suboptimal tumor resection, promoting local recurrence or regional metastasis.

Since early diagnosis, a multidisciplinary approach, both oncological and reconstructive, can obviate the risk of close margins providing effective and stable repair of the defect.

Another issue is represented by the regional lymph node management.

In the past two decades, the practice of sentinel lymph node (SLN) biopsy has been progressively accepted and become widespread, partially obviating the need of a diagnostic lymphadenectomy.

Today, if pre-op staging or the SLN biopsy is positive, the groin dissection keeps playing a main role in maintenance the local disease under control.

A proper groin lymphadenectomy has to extend from Scarpa's apex to the inguinal ligament, but further dissection of external iliac and obturator lymph nodes has always to be considered in the presence of extracapsular spreading, three or more positive unilateral groin lymph nodes, or macrometastasis $>10 \mathrm{~mm}$ [8].

A groin dissection limited to the lymph nodes nearest to the inguinal groove, may achieve the diagnostic purpose, but will fail to avoid a rapid local recurrence in presence of bulky positive pelvic nodes [9].

Lymph node metastasis can rapidly broaden and invade nearby structures, such as femoral vessels [10].

A tumor invasion of the external sheath of the vein can cause thrombosis, but when the malignant process involves a main artery - as common or superficial femoral - acute and massive bleeding has the most chance to occur.

Major drawback of such complex surgery is perioperative life-threatening risk due to age, comorbidities, and general conditions, thus a proper preoperative patient assessment is mandatory.

Adjuvant radiotherapy is usually considered to sterilize the oncological field after surgery, the combination with chemotherapy has been proven to be effective [11], [12].

Alternative to surgery, immunotherapy has been recently proposed for advanced or metastatic SCC, preliminary results seem to be encouraging [13], [14] 


\section{Conclusions}

This case should emphasize that skin ulceration on a non-weight-bearing surface is always suspicious for skin malignancy, an incisional biopsy is easy to perform and consents a rapid diagnosis.

A history of recurrent vulvar SCC should always warn about the risk of late lymph node metastasis even years after a radical excision of the primary tumor and concomitant lymphadenectomy.

The size of the primary tumor (about $3 \mathrm{~cm}$ ) should have led to the diagnosis of advanced SCC, and consequent more aggressive wide excision should have been indicated.

\section{References}

1. Allbritton Jl. Vulvar neoplasms, benign and malignant. Obstet Gynecol Clin North Am. 2017;44(3):339-52. PMid:28778635

2. Luchini C, Nottegar A, Solmi M, Sergi G, Manzato E, Capelli P, et al. Prognostic implications of extranodal extension in nodepositive squamous cell carcinoma of the vulva: A systematic review and meta-analysis. Surg Oncol. 2016;25(1):60-5. https:// doi.org/10.1016/j.suronc.2015.09.005

PMid:26394825

3. van der Steen S, de Nieuwenhof HP, Massuger L, Bulten J, de Hullu JA. New FIGO staging system of vulvar cancer indeed provides a better reflection of prognosis. Gynecol Oncol. 2010;119(3):520-5. https://doi.org/10.1016/j.ygyno.2010.08.036 PMid:20875914

4. Aragona AM, Soderini AH, Cuneo NA. Defining the concept of locally advanced squamous cell carcinoma of the vulva: A new perspective based on standardization of criteria and current evidence. J Gynecol Oncol. 2014;25(4):272-8. https://doi. org/10.3802/jgo.2014.25.4.272

PMid:25142626

5. Skala SL, Ebott JA, Zhao L, Lieberman RW. Predictive value of an alternative strategy for measuring depth and size of stage 1 vulvar squamous cell carcinoma. J Low Genit Tract Dis. 2020;24(3):265-71. https://doi.org/10.1097/

\section{Igt.0000000000000544}

\section{PMid:32366757}

6. Francis JA, Eiriksson L, Dean E, Sebastianelli A, Bahoric B, Salvador S. No. 370-management of squamous cell cancer of the vulva. J Obstet Gynaecol Can. 2019;41(1):89-101. https:// doi.org/10.1016/j.jogc.2018.07.004

\section{PMid:30580832}

7. Topping A, Wilson GR. Diagnosis and management of uncommon cutaneous cancers. Am J Clin Dermatol. 2002;3(2):83-9.

PMid: 11893220

8. Alkatout I, Schubert M, Garbrecht N, Weigel MT, Jonat W, Mundhenke $\mathrm{C}$, et al. Vulvar cancer: Epidemiology, clinical presentation, and management options. Int J Womens Health. 2015;7:305-13. https://doi.org/10.2147/ijwh.s68979

\section{PMid:25848321}

9. de Hullu JA, van der Zee AG. Surgery and radiotherapy in vulvar cancer. Crit Rev Oncol Hematol. 2006;60(1):38-58.

PMid: 16829120

10. Buxant E, Anaf V, Haouari H. Rapid groin recurrence of a vulvar carcinoma with invasion of the femoral vessels and the importance of the initial groin dissection in the staging surgery. Acta Chir Belg. 2005;105(4):418-9. https://doi.org/10.1080/000 15458.2005.11679751

PMid: 16184731

11. Serre E, Raimond E, Diguisto C, Bendifallah S, Body G, Touboul $\mathrm{C}$, et al. Inguino-femoral radiotherapy in vulvar squamous cell carcinoma: Clues to revised indications in patients with only one intracapsular lymph node metastasis. Acta Oncol. 2020;59(5):518-24. https://doi.org/10.1080/02841 86x.2019.1687934

PMid:31718368

12. Xanthopoulos EP, Grover S, Puri PM, Corradetti MN, Heilbroner SP Mitra $\mathrm{N}$, et al. Survival benefit of adjuvant radiation therapy in node-positive vulvar cancer. Am J Clin Oncol. 2018;41(9):845-50. https://doi.org/10.1097/coc.0000000000000393

PMid:30134287

13. Migden MR, Khushalani NI, Chang AL, Lewis KD, Schmults CD, Hernandez-Aya L, et al. Cemiplimab in locally advanced cutaneous squamous cell carcinoma: Results from an openlabel, phase 2, single-arm trial. Lancet Oncol. 2020;21(2):294305. https://doi.org/10.1016/s1470-2045(19)30728-4 PMid:31952975

14. Gellrich FF, Hüning $S$, Beissert $S$, Eigentler T, Stockfleth E, Gutzmer R, et al. Medical treatment of advanced cutaneous squamous-cell carcinoma. J Eur Acad Dermatol Venereol. 2019;33 Suppl 8:38-43. https://doi.org/10.1111/jdv.16024 PMid:31833610 